\title{
Manual Acute PD with Rigid Catheters: A Relook
}

\author{
Mayoor V. Prabhu ${ }^{*}$, , S.V. Subhramanyam², Sinoj Antony ${ }^{2}$ and K.S. Nayak ${ }^{2}$ \\ ${ }^{I}$ Department of Nephrology, Kasturba Medical College, Mangalore (Manipal University) 575003, India \\ ${ }^{2}$ Deccan Hospital, Somajiguda, Hyderabad (AP), India
}

\begin{abstract}
Peritoneal Dialysis (PD) has been an underutilized modality in the treatment of Acute Kidney Injury (AKI). Concerns regarding clearance, fluid removal, infection, complications of therapy, and the hypercatabolic state of AKI has led to PD falling into disrepute. Recent studies have challenged this notion of ineffectiveness. The lower cost, and simplicity of the procedure makes it a particularly attractive option for the developing world which may lack even basic HD facilities, and patients continue to die for want of Renal Replacement Therapy (RRT). We present a review of the available literature about PD in the AKI setting with special reference to the developing world, including the procedure, costs, and effectiveness of the treatment. We also describe the procedure in detail to help 'hand hold' physicians interested in performing this lifesaving procedure.
\end{abstract}

Keywords: Acute PD, AKI, developing countries, PD, RRT.

\section{INTRODUCTION}

PD as a modality of therapy in AKI continues to evoke mixed reactions from physicians.

Significant controversy exists regarding its indications, adequacy, and effectiveness vis a vis hemodialysis (HD) and the more advanced forms of Continuous Renal Replacement Therapy (CRRT). It is a widely held belief that PD compares poorly versus hemodialysis in the more severe and hypercatabolic states of AKI, and is associated with a significantly higher mortality rate in these situations $[1,2]$. This notion has been challenged by the findings of the Brazilian group, which concluded that PD had at least equivalent efficacy [3, 4]. Moreover, recent studies from India and Brazil $[5,6]$ suggest that PD was comparable to intermittent HD/CRRT with regards to mortality, and also had a salutary effect on early recovery of renal function. Also, when compared to the mortality rates reported from other studies which assessed critically ill patients requiring RRT, the PD and HD groups in these studies performed comparably [7, 8]. Clearly, in resource poor settings, PD offers potential benefits that are hard to overlook. For example, in India there still exist remote rural areas where thousands of people lack even basic medical facilities. Hemodialysis equipped hospitals are concentrated largely in the cities and are mostly operated by the private sector making accessibility and cost a major hindrance. The cost of a single session of in hospital/ICU dialysis in a private hospital in India is around \$ 50 , and a huge proportion of Indians cannot afford it [9]. The situation is similarly bleak in several parts of the developing world. PD with rigid catheters and manual exchanges, although considered an

*Address correspondence to this author at the Department of Nephrology, Kasturba Medical College, Mangalore 575003, India; Tel: +918242444590;

E-mail: drprabhunephro@gmail.com archaic practice in full-resource centers in the developed world, remains a logical choice in meeting the needs of patients with AKI in resource-poor settings. For example, centers in Nepal [10] and Tanzania [11] have achieved good results with low mortality, by training medical residents to perform Acute PD.

\section{ACUTE PD WITH RIGID CATHETERS - EXPERIENCE FROM THE DEVELOPING WORLD}

A recent paper reported the experience of a center in Nigeria [12]. This center in Sub Saharan Africa, representing one of the worlds most impoverished areas, used commendable innovation to deliver cost effective PD to its pediatric AKI population, usually the case mix most in need of intervention. Stylet percutaneous catheters, available in the developing world for as little as $\$ 8$ were used as peritoneal access. In an innovative move, nasogastric catheters were also used as access in a few cases. Nasogastric tubes were modified by making fenestrations at the distal end and inserting a rigid metal probe through one of the fenestrations, thereby acting as a stylet. Initially 10-20 $\mathrm{mL} / \mathrm{Kg}$ of fluid was used to fill the abdomen, which was later increased to $30-40 \mathrm{~mL} / \mathrm{Kg}$. Exchanges were performed manually, and a PD record sheet was used to record the dwell time, inflow and outflow. With this regimen, they were able to achieve survival rates of up to $80 \%$. Peritonitis rates of up to $37 \%$ were seen in this study, as expected with the use of percutaneous rigid catheters. Closed PD delivery systems, and tunneled catheters can be used to decrease peritonitis rates [13] but are more expensive. Tenckhoff catheters can be used to prolong the period of dialysis with lower risk of infections [14]. The Nigerian study used commercially available PD fluids to perform the exchanges. However, Intravenous Fluids like Normal Saline, Lactated Ringer's solution and 5\% Dextrose in Water can be suitably modified to freshly prepare fluids for the PD exchanges [15]. 


\section{ACUTE PD: THE PROCEDURE}

Indications: Any patient who has acute kidney injury needing RRT.

Contraindications: Deranged coagulation profile, presence of hernia, distended bowel loops, features of peritoneal adhesions due to repeated intrabdominal surgery or intrabdominal infections like tuberculous peritonitis.

The procedure: Acute PD procedure can be divided into the following four sequential steps:

Step 1- Preparation of the abdomen

Step 2- Priming of the abdomen with fluid,

Step 3- PD catheter insertion and

Step 4- Conducting PD fluid exchanges.

\section{Step 1. Preparation of the Abdomen}

The rectum and urinary bladder are to be emptied before the procedure for which rectal enema and evacuation of urinary bladder may be needed. The abdominal wall hair is to be clipped shaved in case of adult males. The skin of all patients should be cleaned initially with chlorehxidine/isoprolyl alcohol or if chlorhexidine unavailable, povidone iodine scrub and later povidone iodine lotion to ensure sterility. The operator should use sterile gloves, gown and mask. The patient should wear a mask over moth and nose.

\section{Step 2. Priming of the Peritoneal Cavity with Fluid}

Placement of the priming needle in the correct place is a crucial step in the procedure. Instruments required for priming include long wide bore needle or wide bore lumbar puncture needle, two intravenous (IV) fluid of blood administration sets, surgical blade and PD fluid bottles (or bags), 2 liters in case of adults and $50 \mathrm{ml} / \mathrm{kg}$ body weight fluid in case of children (Fig. 1). Most preferred site of PD catheter insertion is in the midline one inch below the umbilicus. The other sites are McBurney's point on right side or similar position in left iliac fossa. After thorough cleaning of the surface of the abdomen with chlorhexidine/isopropyl alcohol or povidone iodine a sterile central hole towel is placed on the abdomen. The IV fluid transfusion set is connected between the PD fluid and the priming needle. Approximately $10 \mathrm{ml}$ of local anaesthesia is instilled at the proposed site of PD catheter placement and a small nick is made at the site with a surgical blade. Prior to introduction of the priming needle the anterior abdominal wall is to be made taut so as to create an intraperitoneal space. The anterior abdominal wall can be made taut by making the patient raise the head against resistance applied on the forehead by the assisting person at the time of introduction of the priming needle. The needle is to be introduced vertically into the abdominal wall, and the layers of the abdominal wall which are to be pierced are skin, linea alba and finally the parietal peritoneum. The most important phenomenon to be experienced at the time of piercing each layer of abdominal wall is initial resistance followed by a feeling of 'giving in'. The final 'giving in' feeling is felt when the parietal peritoneum is pierced after which one should be careful not to advance the needle further as the intestine might get punctured. Once the priming needle positioning is over, the priming needle is anchored on the surface of abdomen with an artery forceps and the infusion of fluid is commenced. Correct position of the priming needle is ascertained by visualisation of good flow of fluid in the air chamber of the IV set. Wrong placement of the needle tip in the intestinal lumen will result in immediate diarrhea and, urinary bladder puncture will cause sudden increase in 'urine' flow which is actually the PD fluid draining out. Hence it is necessary to ascertain absence of intestinal distention and distention of urinary bladder before start of PD.

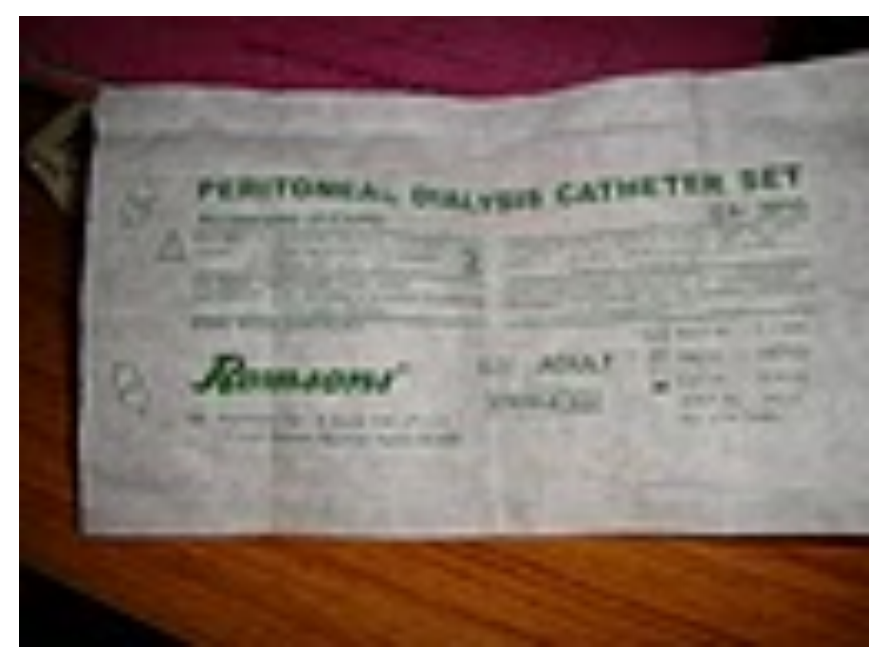

Fig. (1). Prepackaged sterile acute PD kit.

\section{Step 3. PD Catheter Insertion}

Instruments needed are, PD catheter with stylet, two IV sets, a 3 way connector, PD fluid bottles or bags and drain bag (Figs. 1, 2).

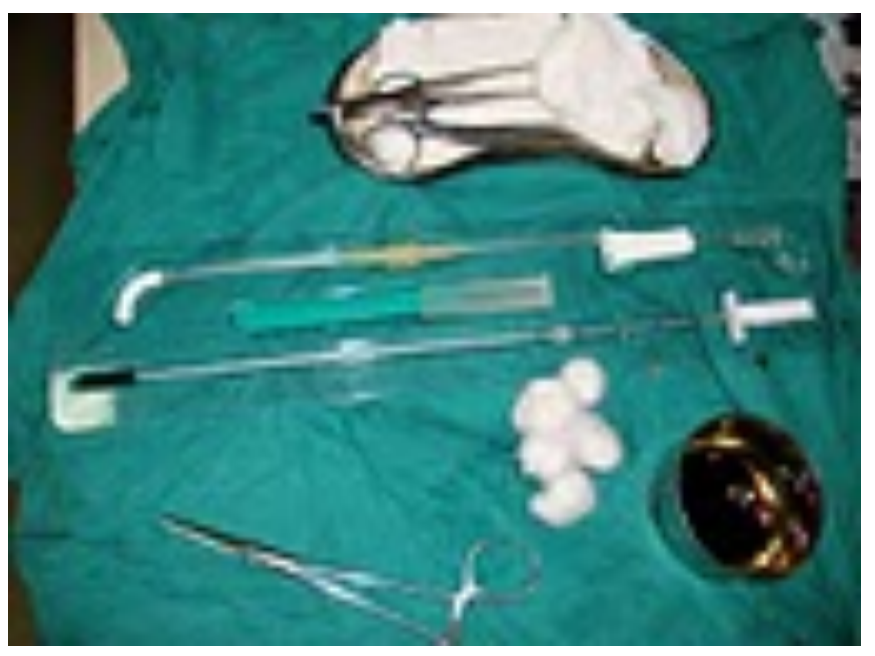

Fig. (2). Acute PD kit with disposables during procedure.

After priming of the required quantity of fluid the priming needle is removed. The PD catheter is kept ready with the stylet well inside the catheter and its sharp tip protruding out. The handle end of the stylet is held firmly in 
one hand and the sharp tip of the stylet is placed vertically on the abdominal wall at the proposed site of entry. With firm pressure, the handle end of the stylet along with the catheter is made to pierce the abdominal wall in a way similar to the priming needle, with a slightly 'cork screw' movement. Having entered the peritoneal cavity there will be a 'giving in' feeling after which the stylet along with the catheter is tilted sagitally in midline such that the tip of stylet points towards the pelvic cavity. The stylet is made to remain in the same position by holding the stylet handle with one hand and PD catheter sheath is advanced with the other hand into the true pelvis. A small rotatory movement of the PD catheter may be necessary while advancing it into the pelvis. The stylet is removed after the PD catheter has been placed well in the pelvis. The movable bead cuffed to the PD catheter is slowly advanced to the abdominal wall with the PD catheter being held in the same position with the other hand. The PD connector tube is then connected to the proximal end of the PD catheter and the other end of the PD connector tube is connected to the 3 way connector. The PD fluid inflow and drainage PD tubes are standard blood or IV fluid administration sets which are connected to the remaining two ports of the three way connector. The primed fluid in the peritoneum is drained out. The speed and quantitiy of fluid drained confirms the success of the PD. A purse string suture is put on the skin around the PD catheter and the suture thread is wrapped around the catheter above the bead so as to anchor the PD catheter.

\section{Step 4. PD Exchanges}

The three way connector is used to regulate the direction of PD fluid. Each fluid cycle has three components a) PD fluid inflow (10 minutes) b) 35 minutes dwell c) drain time (10 to 15 minutes) (Fig. 3). Maintaining sterile connections, exchanges are done at hourly intervals. If hypercatabolic state or hyperkalemia the dwell time is shortened to 10 minutes for faster correction. If extra ultrafiltration is necessary 25 to $100 \mathrm{ml}$ of high concentration dextrose $(25 \%$ or $50 \%$ ) is added into each PD fluid bottle/bag before instilling the fluid into the abdomen. Blood glucose needs to be monitored every 4 hours in diabetics and insulin is to be administered as per sliding scale. Hourly inflow, hourly outflow, total inflow and total outflow are tabulated. A minimum of 24 hours and a maximum of 72 hours of PD is done without significant chance of infection. Most noncatabolic AKI recover with this length of Acute PD.

\section{IS PD EFFECTIVE IN AKI? A LOOK AT THE EVIDENCE}

The role of PD in AKI continues to be the subject of debate. Only 3 prospective RCTs compared PD with extracorporeal therapies, all from developing regions of the world, and all on ICU patients [1, 3, 5]. Interestingly, manual exchanges with rigid catheters were used in 2 of these studies $[1,5]$. The Vietnamese experience [1] concluded that CRRT was significantly superior, while the studies from Brazil and India $[3,5]$ had similar mortality rates. CRRT performed better in most of the expected areas: solute

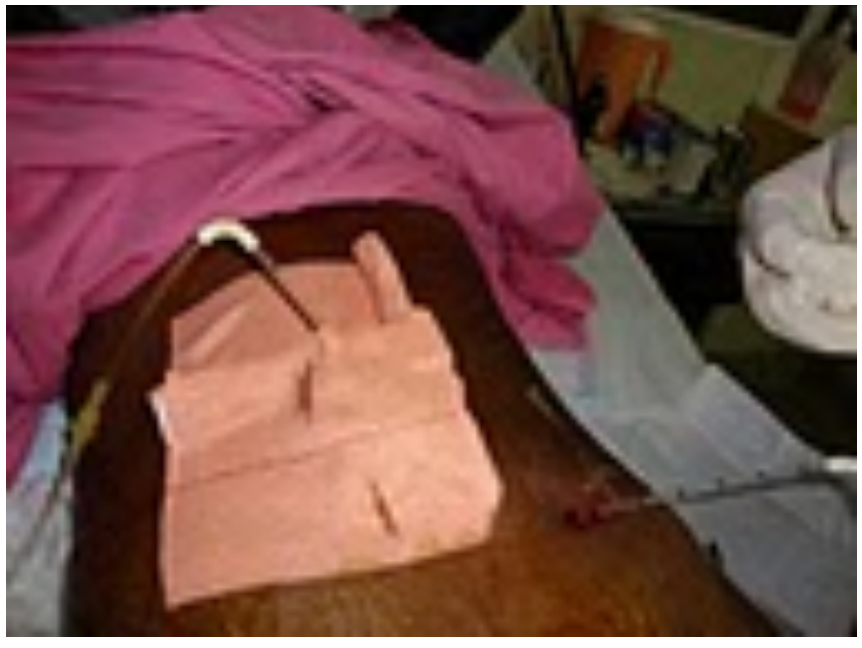

Fig. (3). Acute PD with stiff catheter, after insertion, ready for exchanges.

clearance, fluid control and acidosis control. However, the Indian study showed equivalent hyperkalemia and hemodynamic instability correction. Some of the conclusions of these studies may be attributable to the overall 'dose' of dialysis administered in either arm of the studies, with the better PD results seen in the studies that administered larger 'dose' of dialysis. Ponce and co workers have recently reported, in a series of papers, reasonable evidence of the role of PD in AKI [16-19]. In one of their studies which featured a comparison between high volume $\mathrm{PD}$ and extended daily hemodialysis, there was no difference in median ICU stay, need for chronic dialysis, and mortality between the two groups, while overall $\mathrm{KT} / \mathrm{v}$, ultrafiltration and metabolic and fluid control were superior in the HD group. However, it must be added that these studies used high volume PD with automated cyclers, which is different from the modality we have described in this review. Nevertheless, acute PD with stiff catheters is still practiced in the pediatric setting with gratifying results, even in the developed world. As the authors of a recent commentary in PDI quote :"the clinician needs to exercise practical judgment. Peritoneal dialysis needs to be considered a reasonable treatment for AKI, particularly in low-resource settings in which other forms of RRT are not available" [20].

\section{SAVING LIVES IN THE DEVELOPING WORLD}

Many parts of Sub Saharan Africa, South East Asia and Latin America grapple with a resource crunch, low number and uneven distribution of trained nephrologists, and poor hygiene and sanitation leading to a high incidence of infectious disease [1,11-13]. This is a situation where the incidence of AKI is bound to be high, and training Physicians in acute PD can go a long way in improving healthcare delivery. Fellowship and training programs of the International Society of Nephrology (ISN), and the International Society of Peritoneal Dialysis (ISPD) are catering to the needs of developing countries. We have had the opportunity to host teams from South East Asian Countries under the aegis of the ISPD, and train them in Acute PD. They are able to perform this therapy with 
confidence in their respective countries, with gratifying results. The technique may be further refined/adapted to increase safety and acceptability, by using flexible catheters ( 1 cuffed Tenckhoff) with bedside placement using trocars or Seldinger technique. More institutions should involve themselves in the training programs and help save lives in regions most needing them.

\section{CONCLUSION}

Preventable deaths due to AKI continue to occur in the lesser privileged areas of the world. Acute PD is simple, inexpensive, and effective in most forms of AKI. Governments and private institutions should also contribute to enable efficient transfer of skills of this simple technique to practitioners in the direly deficient developing countries and empower them to save patients dying from what is potentially completely curable AKI. Cheap disposables to perform this treatment should also be made easily available.

\section{CONFLICT OF INTEREST}

The authors confirm that this article content has no conflict of interest.

\section{ACKNOWLEDGEMENTS}

Declared none.

\section{REFERENCES}

[1] Phu NH, Hien TT, Mai NT, et al. Hemofiltration and peritoneal dialysis in infection-associated acute renal failure in Vietnam. $\mathrm{N}$ Engl J Med 2002; 347: 895-902.

[2] Daugirdas JT. Peritoneal dialysis in acute renal failure-why the bad outcome? N Engl J Med 2002; 347: 933-5.

[3] Gabriel DP, Caramori JT, Martin LC, Barretti P, Balbi AL. Continuous peritoneal dialysis compared with daily hemodialysis in patients with acute kidney injury. Perit Dial Int 2009; 29(Suppl 2): S62-71.

[4] Gabriel DP, Caramori JT, Martim LC, Barretti P, Balbi AL. High volume peritoneal dialysis $v s$ daily hemodialysis: a randomized, controlled trial in patients with acute kidney injury. Kidney Int Suppl 2008; (108): S870-93.

[5] George J, Varma S, Kumar S, Thomas J, Gopi S, Pisharody R. Comparing continuous venovenous hemodiafiltration and peritoneal dialysis in critically ill patients with acute kidney injury: a pilot study. Perit Dial Int 2011; 31: 422-9.

[6] Gabriel DP, Caramori JT, Martim LC, Barretti P, Balbi AL. High volume peritoneal dialysis vs daily hemodialysis: a randomized, controlled trial in patients with acute kidney injury. Kidney Int Suppl 2008; (108): S87-93.

[7] Bellomo R, Cass A, Cole L, et al. On behalf of the Renal replacement therapy study investigators. Intensity of continuous renal-replacement therapy in critically ill patients. N Engl J Med 2009; 361: 1627-38.

[8] Palevsky PM, Zhang JH, O'Connor TZ, et al. On behalf of the VA/NIH Acute Renal Failure Trial Network. Intensity of renal support in critically ill patients with acute kidney injury. N Engl J Med 2008; 359: 7-20.

[9] Khanna U. The economics of dialysis in India. Indian J Nephrol $2009 ; 19(1): 1-4$.

[10] Sharma SK, Manandhar D, Singh J, et al. Acute peritoneal dialysis in Eastern Nepal. Perit Dial Int 2003; 23(Suppl 2): S196-9.

[11] Kilonzo KG, Ghosh S, Temu SA, et al. Outcome of acute peritoneal dialysis in northern Tanzania. Perit Dial Int 2012; 32(3): 261-6.

[12] Ademola AD, Asinobi AO, Ogunkunle OO, Nurudeen Yusuf B, Ojo OE. Peritoneal Dialysis in childhood Acute Kidney Injury: Experience in Southwest Nigeria. Perit Dial Int 2012; 32(3): 26772.

[13] Kohli HS, Arora P, Kher V, Gupta A, Sharma RK, Bhaumik SK. Daily peritoneal dialysis using a surgically placed Tenckhoff catheter for acute renal failure in children. Ren Fail 1995; 17: 51-6.

[14] Arora P, Kohli HS, Kher V, et al. Prolonged peritoneal dialysis in acute renal failure using Tenckhoff catheter. Indian Pediatr 1993; 30(8): 981-5.

[15] Phadke KD, Dinakar C. The challenges of treating children with renal failure in a developing country. Perit Dial Int 2001; 21(Suppl 3): S326-9.

[16] Ponce D, Balbi AL, Amerling R. Advances in peritoneal dialysis in acute kidney injury. Blood Purif 2012; 34(2): 107-16. doi: $10.1159 / 000341648$

[17] Ponce D, Berbel MN, Abrão JM, Goes CR, Balbi AL. A randomized clinical trial of high volume peritoneal dialysis versus extended daily hemodialysis for acute kidney injury patients. Int Urol Nephrol 2013; 45(3): 869-78.

[18] Ponce D, Barretti P, Caramori JCT, Balbi A L. Peritoneal Dialysis in acute kidney injury: Brazilian Experience. Perit Dial Int 2012; 32(3): 242-6.

[19] Ponce D, Berbel MN, Regina de Goes C, Almeida CT, Balbi AL. High-Volume peritoneal dialysis in acute kidney injury: Indications and limitations. Clin J Am Soc Nephrol 2012 ; 7(6): 887-94.

[20] Yeates K, Cruz DN, Finkelstain O. Re-examination of the role of peritoneal dialysis to treat patients with acute kidney injury. Perit Dial Int 2012; 32(3): 238-41. 